\section{El paradigma de las Enfermedades Crónicas No Transmisibles: una visión desde la lingüística que crea realidades}

\section{The Non-Communicable Diseases paradigm: a linguistic vision that creates realities}

\section{Señor Editor:}

Durante el transcurso de nuestra historia, como humanidad, se han presentado diversos hitos que han permitido que -como sociedad- mejoremos nuestra percepción y calidad de vida. Sin embargo, desde el comienzo de la Revolución Industrial, esta mejora se ha incrementado exponencialmente con los avances tecnológicos logrados, principalmente en el área de las Ciencias Exactas -en donde el desarrollo de la Epidemiología al permitir el control de brotes, como el caso célebre descrito por John Snow y el cólera en Londres a mediados del siglo XIX y el descubrimiento de la Penicilina, por Sir Alexander Fleming, en 1928, por nombrar algunos- permitió el inicio del control efectivo de las Enfermedades Infectocontagiosas, o Transmisibles, que ha permitido junto con otras medias, cambios en nuestro patrón demográfico, lo que ha significado una evolución desde un patrón de Transición Inicial, caracterizado por una alta natalidad y mortalidad, a una Transición Avanzada, caracterizada por una baja natalidad y mortalidad, que depende del nivel de desarrollo de cada país.

Como es de esperarse, el hecho de evolucionar en la Transición Demográfica, implica que las Enfermedades Infectocontagiosas, Materno-Infantiles y Nutricionales, presenten una disminución de su Incidencia, según el grado de avance, lo que permite que otras enfermedades -que están implicadas en cuanto a los hábitos de vida de la población- presenten una mayor prevalencia e incidencia con el transcurso del tiempo, como lo son las Enfermedades Cardiovasculares, Cáncer, Enfermedades Respiratorias, Digestivas, por solo nombrar algunas de ellas, que han sido nombras como Enfermedades Crónicas no Transmisibles, como contrapartida a las Enfermedades que predominan en la fase de Transición Inicial, y que, en la actualidad, el uso de este término sigue siendo utilizado, a pesar de que -independiente del Modelo de Determinantes de Salud utilizado-existe evidencia suficiente para establecer que los hábitos y patrones societales de una población inciden, directamente, en la aparición de dichas enfermedades, en la carga de enfermedad que generan a un país y que, además, dichos hábitos y patrones son heredables, por imitación, por las generaciones venideras ${ }^{1}$.

Desde el punto de vista lingüístico, el hecho del uso de la negación, como parte de una explicación causal, que, en este caso, correspondería a "Enfermedades Cró- nicas No Transmisibles", establece una condicionalidad en la frase, la negación, tomando un solo argumento que hace referencia a un conjunto de posibilidades y devuelve el complemento de ese conjunto, en donde las personas utilizan un pequeño margen, que otorgan a la negación, con el fin de minimizar todos los resultados posibles $^{2}$. Es decir, en términos simples, buscamos simplificar un concepto o idea con el fin de obviar otras posibilidades que pueden ser más complejas de tratar $y$, por ende, que requerirán más esfuerzo y/o trabajo para poder definir u obtener su significado.

Bajo la premisa anterior, el hecho de usar una condicional negativa en el lenguaje, genera una realidad en donde la inquietud por saber o determinar las condiciones que afectan a dicho proceso, se desvanecen, lo que logra una invisibilidad del tema en cuestión ${ }^{3}$, lo que invita a las personas o grupos a normalizar una situación que, eventualmente, pudiese tener alternativas que puedan ofrecer mejores resultados, tanto individuales como colectivos.

Esto se ha reflejado ya en las temáticas internacionales y nacionales, en donde se propuesto renombrar a las Enfermedades Crónicas No Transmisibles como Enfermedades o Condiciones de Transmisión Social ${ }^{4}$, lo que permite -al quitar la negación-dar un hincapié más profundo a las variables que condicionan la aparición de dichas enfermedades -tanto antropológicas como sociales-invitando no solo a grupos de expertos a debatir con más ahínco sobre dichos problemas, sino que se agregan a ellos la sociedad como parte de la problemática y de la solución, creando una realidad en donde este tema queda visible y que impide el hecho de negación, pues explicita que la sociedad -como un todo- es responsable del problema.

Las consecuencias que trae el renombrar este concepto implica que todos los actores de la sociedad tiene voz, en su respectiva área, para ofrecer soluciones y mejoras que promuevan y ayuden a prevenir la gran cantidad de enfermedades que, por nuestros hábitos de vida, se desarrollan en nuestra sociedad, fomentando el trabajo del intersector en forma coordinada, permitiendo mejorías sustanciales en el nivel de vida de los distintos asentamientos humanos, lo que, a largo plazo, permite optimizar los-escasos-recursos disponibles de los cuales se disponen.

El cambio del paradigma a Enfermedades Crónicas o Condiciones de Trasmisión Social es complejo, aún en el mundo de la Salud, dado el recelo por el cambio que existe en las definiciones conceptuales que utilizamos para definir los estados de salud y que, en primera instancia, este nuevo concepto no lograr incorporar -adecuadamente- a las enfermedades congénitas o degenerativas ${ }^{4}$, sin embargo, si queremos optimizar el abordaje de la amplia gama de patologías que envuelve la Transmisión Social, que abarca tanto Enfermedades Transmisibles como No Transmisibles, no podemos 
esperar resultados distintos si seguimos definiendo y abarcando los problemas de la misma manera.

Gonzalo Núñez Muñoz ${ }^{1, a, b}$ ${ }^{1}$ Escuela de Salud Pública "Dr. Salvador Allende", Universidad de Chile, Santiago, Chile. ${ }^{a}$ Médico Residente Especialidad Médica en Salud Pública, Universidad de Chile, Santiago, Chile.

${ }^{b} M B A$.

\section{Referencias}

1. Christakis NA, Fowler JH. Social contagion theory: examining dynamic social networks and human behavior. Stat Med [Internet]. 2013 Feb 20 [citado el 24 de marzo de 2019]; 32 (4): 556-77. Available from: http://www.ncbi.nlm.nih. gov/pubmed/22711416.

2. Khemlani S, Orenes I, Johnson-Laird PN. Negation: A theory of its meaning, representation, and use. J Cogn Psychol [Internet]. 2012 Aug [citado el 24 de marzo de 2019]; 24 (5): 541-59. Available from: http://www.tandfonline.com/ doi/abs/10.1080/20445911.2012.660913.

3. Echeverría R. Ontología del Lenguaje. $6^{a}$ Edición. Comunicaciones Noreste Ltda.; 2003. 52 p.

4. Allen LN, Feigl AB. Reframing non-communicable diseases as socially transmitted conditions. Lancet Glob Heal [Internet]. 2017 Jul 1 [citado el 23 de marzo de 2019]; 5 (7): e644-6. Available from: http://www.ncbi.nlm.nih.gov/ pubmed/28619214.

Fuente de apoyo financiero: sin financiamiento.

Correspondencia a:

Gonzalo Núñez Muñoz

Alameda 2601 D-1304, Santiago.

gonzalo.nunez@ug.uchile.cl 